\title{
Hobnail hemangioma on the knee: A rare entity
}

\section{Samia Mrabat', Zakia Douhi', Sara Elloudi', Hanane Baybay', Fatima Zahra Mernissi', Amal Douida' ${ }^{2}$, Layla Tahri Elousrouti ${ }^{2}$, Hinde El Fatemi ${ }^{2}$}

\author{
${ }^{1}$ Department of Dermatology, University Hospital Hassan II, Fes, Morocco, ${ }^{2}$ Department of Anatomopathlogy, University \\ Hospital Hassan II, Fes, Morocco
}

Corresponding author: Dr. Samia Mrabat, E-mail: samiamrabat91@gmail.com

Sir,

A 8-year-old girl presented with a 4-year history of a single, asymptomatic plaque on the knee. The lesion started as an erythematous papule and later gradually increased in size. There was no history of fluid filled lesions, trauma, or insect bite preceding the lesion. Cutaneous examination revealed a single non-tender oval plaque of $2 \times 2 \mathrm{~cm}$, present on the right side of the knee (Fig. 1). The plaque had a violaceous center and brownish hue at the periphery, giving a targetoid appearance. On dermoscopy, there were lagoon-like areas, rosettes and Linear white structures surrounding these lagoon-like areas were prominent (Fig. 2). A pigmented network was seen at the periphery. A skin biopsy, performed on the knee,showed irregularly dilated vascular structures in the superficial and middermis lined by prominent hobnail endothelial cells. In the deeper dermis, rather narrow neoplastic vessels with collagen dissection were found (Fig. 3). Finally, a diagnosis of hobnail hemangioma was made.

Hobnail hemangioma $(\mathrm{HH})$ is a benign vascular lesion showing peculiar endothelial cells' morphology, confined to the superficial and mid dermis. It was first described as targetoid hemosiderotic hemangioma in 1988 [1]. It may be seen both in patient are in their 20s or 30 s, and it is rarely in children. Typically presents as a small and solitary papule or macule, red, purple, or brown, located more frequently on the proximal extremities or the trunk [1,2]. The characteristic targetoid appearance is owing to peripheral hemorrhage and hemosiderin deposition. The most typical dermoscopic findings are a homogeneous central area, red and dark lagoon-like, peripheric red-violaceous ring, whitish structures, peripheric

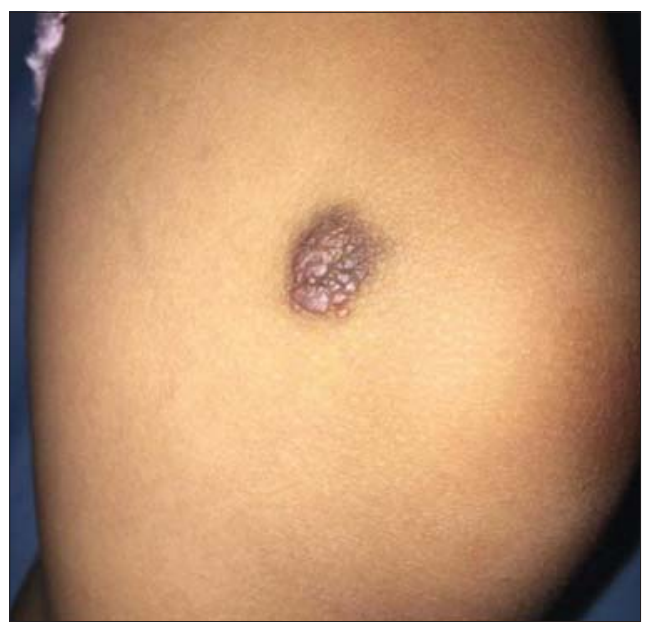

Figure 1 : Clinical aspect : oval plaque of $2 \times 2 \mathrm{~cm}$ on the right side of the knee. The plaque had a violaceous center and brownish hue at the periphery, giving a targetoid appearance.

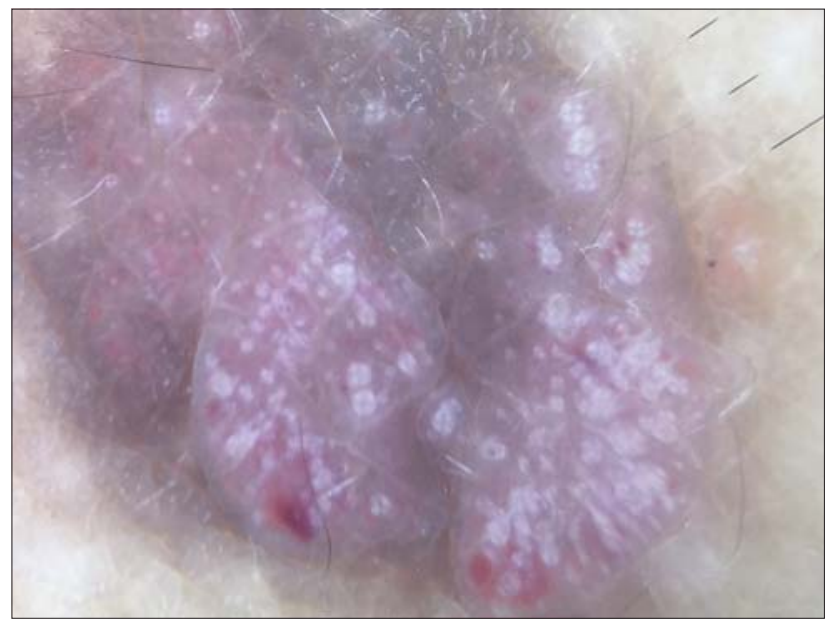

Figure 2 : Dermoscopic aspect : lagoon-like areas, rosettes and linear white structures surrounding these lagoon-like red areas with a delicate pigmented network at the periphery

vascular structures, yellowish intermediate areas, and a peripheral pigment network $[3,4]$. Histopathologic

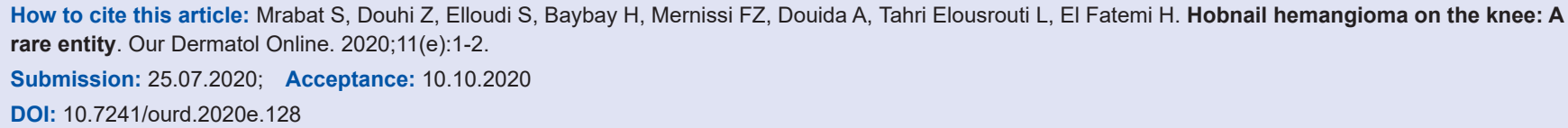


www.odermatol.com

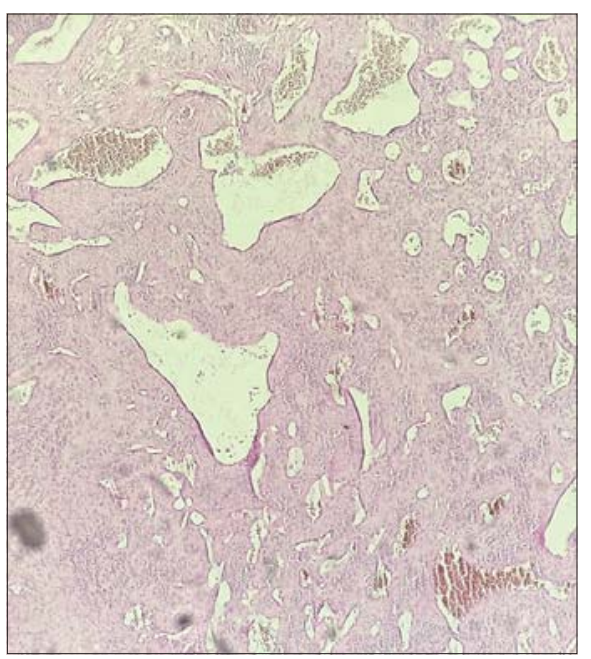

Figure 3 : Histopathological examination revealed irregularly dilated vascular structures in the superficial and middermis lined by prominent hobnail endothelial cells. In the deeper dermis, narrow neoplastic vessels with collagen dissection were found.

features of hobnail hemangioma vary according to the duration or age of the individual lesion, generally we find a biphasic pattern. In the upper dermis, a number of dilated vessels were present. Their endothelial cells were plump with intraluminal papillary projections, showing a 'hobnail' appearance. In the deeper dermis, vascular spaces formed slitlike spaces. Intense red blood cells extravasation and numerous siderophages were also observed [1-5]. The clinical differential diagnosis in children includes vascular tumors and malformations [3]. The clinical setting, dermoscopic and Histopathologic features are helpful in differentiating these entities [4,5]. Therefore, local excision or excisional biopsy may be done. Recurrence after excision has not been reported [6].

\section{Consent}

The examination of the patient was conducted according to the principles of the Declaration of Helsinki.

The authors certify that they have obtained all appropriate patient consent forms, in which the patients gave their consent for images and other clinical information to be included in the journal. The patients understand that their names and initials will not be published and due effort will be made to conceal their identity, but that anonymity cannot be guaranteed.

\section{CONFLICT OF INTEREST}

The authors declare no conflict of interest

\section{REFERENCES}

1. Porriño-Bustamante ML, Aneiros-Fernández J, Retámero JA, Fernández-Pugnaire MA. Hobnail Hemangioma With an Unusual Clinical Presentation. J Cutan Med Surg. 2017;21:164-6.

2. Krishna CV, Reddy GM, Senthil Kumar AL, Mohan Rao AV. Hobnail hemangioma on the trunk. Dermatol Online J. 2013;19:18179.

3. Ibrahim M, Shwayder T. Hobnail hemangioma in a nine-year-old boy: a rare case presented with dermoscopy. Dermatol Online J. 2010;16:7.

4. Biondo G, Pistone G, Bongiorno MR. A pigmented papule acting like a playful ghost: dermoscopy of three targetoid hemosiderotic hemangiomas. G Ital Dermatol Venereol. 2018;153:685-91.

5. Sahin MT, Demir MA, Gunduz K, Özturkcan S, Türel-Ermertcan A. Targetoid hemosiderotic haemangioma: dermoscopic monitoring of three cases and review of the literature. Clin Exp Dermatol. 2005;30:672-6.

6. Takayama R, Ueno T, Futagami A, Ansai S, Fukumoto T, Saeki H. Hobnail hemangioma: A Case Report. J Nippon Med Sch. 2015;82:151-5.

Copyright by Samia Mrabat, et al. This is an open-access article distributed under the terms of the Creative Commons Attribution License, which permits unrestricted use, distribution, and reproduction in any medium, provided the original author and source are credited.

Source of Support: Nil, Conflict of Interest: None declared. 